\title{
Processing of Lithium Niobate and Potassium Lithium Niobate Films Using Environmentally-Friendly Aqueous Precursor Solutions
}

\author{
Satomi ONO and Shin-ichi HIRANO* \\ Nagoya Municipal Industrial Research Institute, 3-4-41, Rokuban, Atsuta-ku, Nagoya 456-0058 \\ *Nagoya University, Furo-cho, Chikusa-ku, Nagoya 464-8601
}

\begin{abstract}
Lithium niobate $\left(\mathrm{LiNbO}_{3}\right)$ and potassium lithium niobate $\left(\mathrm{K}_{3} \mathrm{Li}_{2} \mathrm{Nb}_{5} \mathrm{O}_{15}\right)$ films can be prepared using environmentally-friendly aqueous precursor solutions. The process is reviewed by focusing on chemical properties and structure of a water soluble $\mathrm{Li}-\mathrm{Nb}$ precursor molecule. The $\mathrm{Li}-\mathrm{Nb}$ precursor molecule appears to be an oligomer having -O-Nb-O-Li-O- bonds with $\left[\mathrm{NbO}_{3}(\mathrm{OH})_{3}\right]^{4-}$ octahedral structure. The water solubility of the oligomer molecule may be due to the hydroxy groups surrounding the molecule, which makes the solution alkaline. This alkaline solution can be neutralized by acetic acid. High quality $\mathrm{LiNbO}_{3}$ and $\mathrm{K}_{3} \mathrm{Li}_{2} \mathrm{Nb}_{5} \mathrm{O}_{15}$ films crystallize by heat-treatment at low temperatures. The low crystallization temperature of the $\mathrm{LiNbO}_{3}$ film can be achieved because the precursor film contains no carbon residues, and the precursor molecule is designed to have the skeletal structure in the $\mathrm{LiNbO}_{3}$ crystal. Micro-patterning of $\mathrm{LiNbO}_{3}$ films are conducted by means of a coating process using neutralized aqueous precursor solution in the photolithographic technique. Aqueous precursor solutions with controlled composition can lead to the development of the processing of high quality powders and films in lead-free piezoelectric $(\mathrm{K}, \mathrm{Na}, \mathrm{Li}) \mathrm{NbO}_{3}$ ceramics and $\mathrm{LiNbO}_{3}$ waveguides.
\end{abstract}

[Received August 24, 2007; Accepted October 18, 2007]

Key-words : Metal alkoxide, Precursor molecule, Aqueous solution, Film, Lithium niobate, Potassium lithium niobate, Patterning

1. Introduction

Single crystal $\mathrm{LiNbO}_{3}$ is a ferroelectric material which has piezoelectric, electro-optic, nonlinear optic and photorefractive properties. These properties are exploited in applications such as waveguides, surface acoustic wave devices and holographic memory. High-quality stoichiometric $\mathrm{LiNbO}_{3}$ films have been under study for the miniaturizing and integrating of optical waveguide devices.

Several methods have been reported for preparing $\mathrm{LiNbO}_{3}$ films from metal alkoxides. ${ }^{1)-19)}$ Generally, the metal alkoxides have strong reactivity to water, and are easily hydrolyzed and polymerized in the atmosphere. Organic solvents and chelating reagents are therefore used to prevent the alkoxy group to hydrolyzing and polymerizing, and to stabilize the solution. Recently, however, industry prefers environmentally-friendly processes using water based solutions rather than flammable organic solvents.

We have studied the processing of functional ceramics using water based solutions for more than 10 years and have developed a processing method for $\mathrm{LiNbO}_{3}$ and $\mathrm{K}_{3} \mathrm{Li}_{2} \mathrm{Nb}_{5} \mathrm{O}_{15}$ (KLN) films using aqueous precursor solutions. ${ }^{16)}{ }^{21}$ ) We found that lithium niobium ( $\mathrm{Li}-\mathrm{Nb}$ ) hydroxide, which is prepared by complete hydrolysis of lithium niobium $(\mathrm{Li}-\mathrm{Nb})$ double alkoxide derived from lithium and niobium alkoxides, is soluble in water. $\mathrm{Li}-\mathrm{Nb}$ hydroxide aqueous solution is also recognized to be useful as a precursor solution for preparing $\mathrm{LiNO}_{3}$ powders and films.

Environmentally toxic metals are currently prohibited by European regulations denoted as the RoHS (restriction of the use of certain hazardous substances in electrical and electronic equipment) Directive. This Directive bans the sale in the EU of new electrical and electronic equipment containing more than agreed levels of lead, cadmium, mercury, hexavalent chromium, polybrominated biphenyl and polybrominated diphenyl ether flame retardants.

Lead zirconium titanate (PZT) ceramics are well known to be a superior piezoelectric material, which have widely been used in many fields. In the view of the toxicity of lead, the development of lead free piezoelectric ceramics substituting PZT is vital. Of the various lead-free piezoelectric materials, ceramics based on alkali metal niobates $(\mathrm{K}, \mathrm{Na}, \mathrm{Li}) \mathrm{NbO}_{3}$ are promising candidates, and have been studied intensively. ${ }^{22)}-30$ )

Composition-controllable aqueous precursor solutions derived from metal alkoxides are useful for preparing lead-free piezoelectric $(\mathrm{K}, \mathrm{Na}, \mathrm{Li}) \mathrm{NbO}_{3}$ ceramics. High quality piezoelectric ceramics composed of dense crystalline nano-particles might be synthesized by heat-treatment below $1000^{\circ} \mathrm{C}$ using such composition controlled aqueous precursor solutions.

In this review, we describe the chemistry of alkoxide-derived aqueous precursor solutions in the processing of the $\mathrm{LiNbO}_{3}$ and KLN films, and propose the use of aqueous precursor solutions for processing other alkali-metal niobate materials.

\section{Preparation of aqueous precursor solution derived from} metal alkoxide

\subsection{Hydrolysis of metal alkoxide}

Metal alkoxide is a metal organic compound. It is considered to be an alcohol derivative in which hydroxylic hydrogen is replaced by metal, and is represented as $\mathrm{M}(\mathrm{OR})_{\mathrm{n}}(\mathrm{M}$; metal, R; alkyl). Metal alkoxide is a strong Lewis acid and is highly reactive because of its highly electronegative alkoxy group. The metal is therefore readily attacked by the nucleophilic substitution reaction and is hydrolyzed even by the water in humid air. Metal alkoxides should therefore be handled carefully under a dry nitrogen atmosphere in a glove box. Chemical reactions of the metal alkoxide are shown in Eqs. (1)-(3). When the metal alkoxide is hydrolyzed, polymerization proceeds by dehydration and dealcoholization, leading to gelation in the solution and generating hydrate oxides and hydroxide precipitates having -M-O-M-Obonds. The hydrolysis rates depend on the electronegativity of the metal, the carbon number and the stereo structure of the alkoxy groups (-OR). By controlling the amount of water used to hydrolyze the metal alkoxide, partially hydrolyzed alkoxide oxides $\left(\mathrm{MO}_{\mathrm{n}}(\mathrm{OR})_{\mathrm{x}}\right)$ can be produced. 


$$
\begin{aligned}
& \mathrm{M}(\mathrm{OR})_{\mathrm{n}}+x \mathrm{H}_{2} \mathrm{O} \rightarrow \mathrm{M}(\mathrm{OH})_{\mathrm{x}}(\mathrm{OR})_{\mathrm{n}-\mathrm{x}}+x \mathrm{ROH} \\
& \mathrm{MOH}+\mathrm{MOH} \rightarrow \mathrm{MOM}+\mathrm{H}_{2} \mathrm{O}(\text { dehydration }) \\
& \mathrm{MOH}+\mathrm{MOR} \rightarrow \mathrm{MOM}+\mathrm{ROH}(\text { dealcoholization })
\end{aligned}
$$

Investigation of the controlling conditions is needed for preparation of the aqueous precursor solution from metal alkoxides, to: 1) control the hydrolysis rates of metal alkoxides, 2) protect the hydroxy groups from polymerization by replacement with appropriate groups such as acetates, 3 ) control $\mathrm{pH}$ of the solution so as to dissolve the metal hydroxide generated by hydrolysis of the metal alkoxide. To evaporate the alcohols generated after hydrolysis of the metal alkoxides out of the water solution, it is recommended to select the metal alkoxides, which are derivatives of alcohols having boiling points below that of water, such as methanol $\left(64.7^{\circ} \mathrm{C}\right)$, ethanol $\left(78.3^{\circ} \mathrm{C}\right), 1$-propanol $\left(97.2^{\circ} \mathrm{C}\right), 2$-propanol $\left(82.3^{\circ} \mathrm{C}\right)$ and 2 -methyl-2-propanol $\left(82.5^{\circ} \mathrm{C}\right)$. Although the alcohol cannot be excluded completely from the solution, the remaining alcohol content can be reduced to the level at which the solution is not flammable. We have succeeded in preparing aqueous precursor solutions for coating silica, ${ }^{31)}$ alumina and zirconia films, using silicon alkoxide, aluminum alkoxide and zirconium alkoxide respectively, by finding the optimal conditions.

\subsection{Preparation of aqueous precursor solutions for $\mathrm{LiNbO}_{3}$ and $\mathrm{KLN}$ films}

Hirano et al. have reported a processing method for $\mathrm{LiNbO}_{3}$ powder, film and fiber by heat-treatment at low temperatures using $\mathrm{Li}-\mathrm{Nb}$ double alkoxide ethanol solutions. This $\mathrm{Li}-\mathrm{Nb}$ double alkoxide ethanol solution is prepared by dissolving lithium ethoxide (99.9\%) and niobium ethoxide (99.9\%) in absolute ethanol in molar ratio $1: 1$, and refluxing for $24 \mathrm{~h}$ under a dry nitrogen atmosphere. ${ }^{1)-6)}$ A partially hydrolysis of the $\mathrm{Li}-\mathrm{Nb}$ double alkoxide ethanol solution could lead to preparation of the precursor solution for synthesizing $\mathrm{LiNbO}_{3}$ films.

Partially hydrolyzed precursor solution is used because complete hydrolysis of the $\mathrm{Li}-\mathrm{Nb}$ double alkoxide generates precipitates in the solution. The inhomogeneous suspension cannot be used as precursor solution, so that clear and homogeneous partially hydrolyzed double alkoxide ethanol solution is used. However, the partially hydrolyzed precursor solution must be handled under dry nitrogen atmosphere, so that hydroxide precipitates are not generated by hydrolysis in the solution under moist atmospheres.

Processing with aqueous solution gives much less carbonic residue in coating films than with the alkoxide ethanol solution. We found that $\mathrm{Li}-\mathrm{Nb}$ hydroxide, which is precipitated by complete hydrolysis of the lithium niobium double alkoxide, is not soluble in ethanol, but soluble in water to produce an alkaline solution. ${ }^{16)}$ This alkaline aqueous solution ( $\left.\mathrm{pH} 11\right)$ can be used as a precursor solution for coating. The aqueous precursor solution is not required to be handled under dry nitrogen atmosphere, because the completely hydrolyzed precursor solution does not react with any further water. The aqueous precursor solution is very stable, and can be stored for at least 10 years without precipitation.

The important points in the processing of the aqueous precursor solution are as follows. 1) The homogeneous $\mathrm{Li}-\mathrm{Nb}$ double alkoxide should be prepared by refluxing at least $20 \mathrm{~h}$. 2) Evaporation of ethanol solvent from the $\mathrm{Li}-\mathrm{Nb}$ hydroxide suspension after complete hydrolysis should be carried out at room temperature in a vacuum. 3) The heating temperature should be below $80^{\circ} \mathrm{C}$ for concentrating the $\mathrm{Li}-\mathrm{Nb}$ hydroxide solution, to inhibit generation of insoluble precipitates by
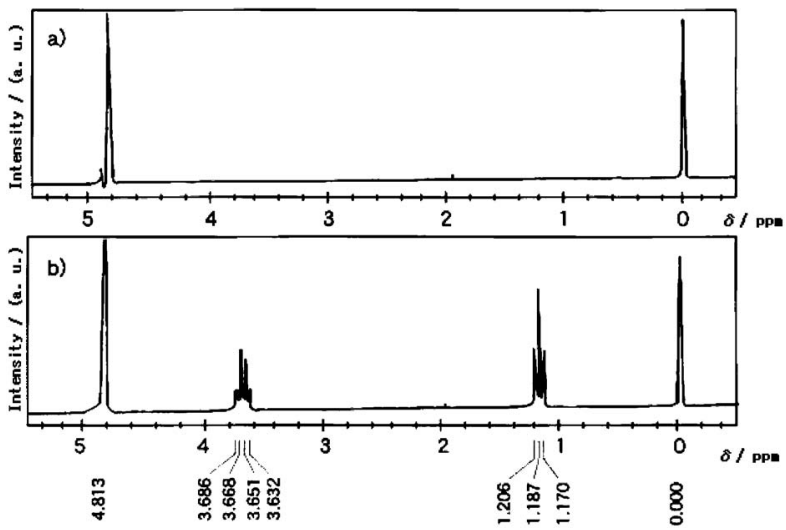

Fig. 1. ${ }^{1} \mathrm{H}$ FT-NMR spectra of a) gel film, b) precipitate derived from unhydrolyzed double alkoxide, $0 \mathrm{ppm}$ : $\left(\mathrm{CH}_{3}\right)_{3} \mathrm{SiCH}_{2} \mathrm{CH}_{2} \mathrm{CO}_{2}$ $\mathrm{Na}$.

polymerization. Dehydration and polymerization of the $\mathrm{Li}$ $\mathrm{Nb}$ hydroxide is accelerated by heating and $\mathrm{Li}-\mathrm{Nb}$ hydroxide powder dried over $100^{\circ} \mathrm{C}$ is insoluble in water. In contrast, freeze-dried $\mathrm{Li}-\mathrm{Nb}$ hydroxide powder is readily soluble in water.

Inductively coupled plasma atomic emission spectroscopic analysis showed that the composition of the gel film prepared from the aqueous precursor solution has the correct stoichiometry $\mathrm{Li} / \mathrm{Nb}=1.0$

The ${ }^{1} \mathrm{H}$ nuclear magnetic resonance (NMR) spectrum of the gel film solution dissolved in $\mathrm{D}_{2} \mathrm{O}$ was analyzed to determine whether the ethoxy group residues remain. No ${ }^{1} \mathrm{H}$ signals derived from ethoxy group $\left(-\mathrm{O}-\mathrm{CH}_{2} \mathrm{CH}_{3}\right)$ were detected in the ${ }^{1} \mathrm{H}$ NMR spectrum (see Fig. 1(a)). In contrast, the ${ }^{1} \mathrm{H}$ NMR spectrum of the $\mathrm{D}_{2} \mathrm{O}$ solution of the precipitates prepared directly from the unhydrolyzed $\mathrm{Li}-\mathrm{Nb}$ double alkoxide gave rise to ${ }^{1} \mathrm{H}$ signals ascribed to a methyl group triplet at 1.170 , 1.187 and $1.206 \mathrm{ppm}$ and a methylene group quartet at 3.632, $3.651,3.668$ and $3.686 \mathrm{ppm}$, (Fig. 1(b)). Upon adding a small amount of ethanol to the solution, the signals ascribed to the ethoxy group were enhanced, so that these signals were identified as due to the ethoxy group related to free ethanol. These results indicate that $\mathrm{Li}-\mathrm{Nb}$ double alkoxide is easily hydrolyzed by water at room temperature, and that the $\mathrm{Li}-\mathrm{Nb}$ hydroxide solution does not contain any ethanol after the evaporation.

First, we speculate that the $\mathrm{Li}-\mathrm{Nb}$ hydroxide is soluble in water under alkaline conditions. If the water solubility of the $\mathrm{Li}-\mathrm{Nb}$ hydroxide is due to the alkaline $\mathrm{pH}$, other aqueous precursor solutions can be expected to be prepared similarly to sodium niobate and potassium niobate films, using stronger alkali than lithium, sodium or potassium. We examined the water solubilities of $\mathrm{Na}-\mathrm{Nb}$ and $\mathrm{K}-\mathrm{Nb}$ hydroxides, which were prepared by the complete hydrolyses of $\mathrm{Na}-\mathrm{Nb}$ and $\mathrm{K}-\mathrm{Nb}$ double alkoxides.

$\mathrm{The} \mathrm{Na}-\mathrm{Nb}$ hydroxide was soluble in water, but the aqueous solution became turbid due to precipitation upon concentrating the solution by heating. Clear and homogeneous $\mathrm{Na}-\mathrm{Nb}$ aqueous solution can exist in concentrations less than 0.3 $\mathrm{mol} / \mathrm{L}$ without precipitates.

$\mathrm{K}-\mathrm{Nb}$ hydroxide precipitate, which was obtained by complete hydrolysis of the $\mathrm{K}-\mathrm{Nb}$ double alkoxide using 1propanol or 2-propanol as a solvent, was scarcely soluble in water. The $\mathrm{pH}$ of the $\mathrm{K}-\mathrm{Nb}$ hydroxide suspension was close to neutral with polymerization. We then examined the solubility 
of the niobium hydroxide precipitate in potassium hydroxide solution. Niobium hydroxide precipitates are soluble in potassium hydroxide solution in the molar ratio $\mathrm{K}: \mathrm{Nb}=2: 1$.

The water solubilities of the alikali-metal-Nb hydroxides prepared from complete hydrolysis of the double alkoxides decrease as $\mathrm{Li}>\mathrm{Na}>\mathrm{K}$. Table 1 shows the solubilities of the alkali-metal hydroxides in water, which increase as $\mathrm{Li}<\mathrm{Na}$ $<\mathrm{K}^{32}$ The solubilities of the alkali-metal-Nb hydroxides derived from the metal alkoxides show the reverse tendency. The solubilities of alkali-metal-Nb hydroxides derived from the metal alkoxides do not correspond to those of their alkalimetal hydroxides.

The structure of the $\mathrm{Li}-\mathrm{Nb}$ precursor molecule is an intriguing question. In considering the aqueous solution chemistry of niobium, the niobate isopolyanions, $\left[\mathrm{H}_{x} \mathrm{Nb}_{6} \mathrm{O}_{19}\right]^{(8-x)-}$ ions $(x=0,1$, or 2$)$ and $\mathrm{Nb}_{6} \mathrm{O}_{19}{ }^{8-}$ ions, are known to exist in aqueous soluon, and are stable only at higher $\mathrm{pH}$; they precipitate at around $\mathrm{pH} 7 . .^{33)}$

Eichorst et al. analyzed the structure of $\mathrm{Li}-\mathrm{Nb}$ double alkoxide $\left(\mathrm{LiNb}\left(\mathrm{OCH}_{2} \mathrm{CH}_{3}\right)_{6}\right)$, and reported that $\mathrm{Li}-\mathrm{Nb}$ double alkoxides were helical polymers composed of alternating $\mathrm{Nb}\left(\mathrm{OCH}_{2} \mathrm{CH}_{3}\right)_{6}$ octahedra cis-linked by severely distorted tetrahedral $\mathrm{Li}$ atoms. ${ }^{34}$

Polymer with high molecular weight is not considered to be soluble in water, except for the materials like polyvinyl alcohol having many hydrophilic groups as hydroxy groups. The polymer solutions have high viscosity. The $\mathrm{Li}-\mathrm{Nb}$ precursor molecule is soluble in water, and the $\mathrm{Li}-\mathrm{Nb}$ precursor solution $(0.52 \mathrm{~mol} / \mathrm{L})$ has slightly higher viscosity $(1.2 \mathrm{mPa} \cdot \mathrm{s}$ at $\left.22^{\circ} \mathrm{C}\right)$, than water $\left(0.94 \mathrm{mPa} \cdot \mathrm{s}\right.$ at $\left.22^{\circ} \mathrm{C}\right)$. These facts suggest that the $\mathrm{Li}-\mathrm{Nb}$ precursor molecule is not a polymer with high molecular weight, but an oligomer having hydroxy groups. The structure of the $\mathrm{Li}-\mathrm{Nb}$ precursor molecular in aqueous solution might be similar to that of the double alkoxide in which ethoxy groups are substituted for hydroxy groups (Fig. 2(a)). The oligomer molecule could have -O-Nb-O$\mathrm{Li}-\mathrm{O}-$ bonds, with $\left[\mathrm{NbO}_{3}(\mathrm{OH})_{3}\right]^{4-}$ octahedra combined with tetrahedral $\mathrm{Li}^{+}$ions (Fig. 2(b)). The water solubility of the oligomer molecule may be due to the hydroxy groups surrounding the molecule. The precursor molecules dehydrate in the hydroxy groups and polymerize, followed by crystallization to $\mathrm{LiNbO}_{3}$ through partially hydrolyzed oxides, with $\mathrm{LiNbO}_{\mathrm{m} / 2}(\mathrm{OH})_{6-\mathrm{m}}$ intermediates.

The electronegativity of the alkali metal is a significant factor. The hydrolysis rate of the double alkoxide depends on the electronegativity of the metal. Hydrolysis and polymerization of the double alkoxide is further accelerated, since the alkali metal has smaller electronegativity. The electronegativity of the alkaline metals decreases as $\mathrm{Li}>\mathrm{Na}>\mathrm{K}$, as shown in Table $1 .^{35)}$ The polymerization rate for generation of insoluble precipitates therefore increases as $\mathrm{Li}<\mathrm{Na}<\mathrm{K}$, giving high water solubility of alkoxide-derived $\mathrm{Li}-\mathrm{Nb}$ hydroxide, and low solubililty of alkoxide-derived $\mathrm{K}-\mathrm{Nb}$ hydroxide.

2.3 Neutralization of the aqueous precursor solution by acetic acid

A 2-dimensional slab-type $\mathrm{LiNbO}_{3}$ waveguide can easily be fabricated by coating $\mathrm{LiNbO}_{3}$ film over the substrate. However, 3-dimensional ridge-type waveguides, in which a light is simultaneously trapped in the horizontal and vertical directions, are required in application of $\mathrm{LiNbO}_{3}$ films to optical devices such as optical modulators and optical switches. To fabricate these, we sought to pattern the $\mathrm{LiNbO}_{3}$ films using the photolithography technique, which is widely used for micro fabrication of IC. However, the alkaline aqueous precursor solution was not suitable for coating patterned a)

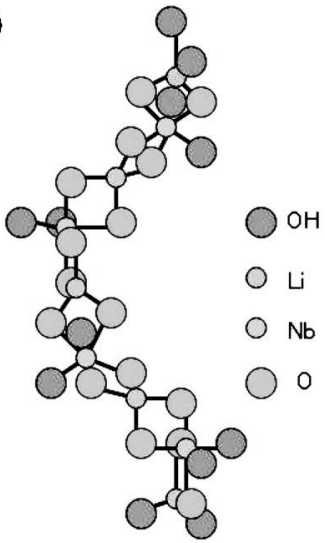

b)

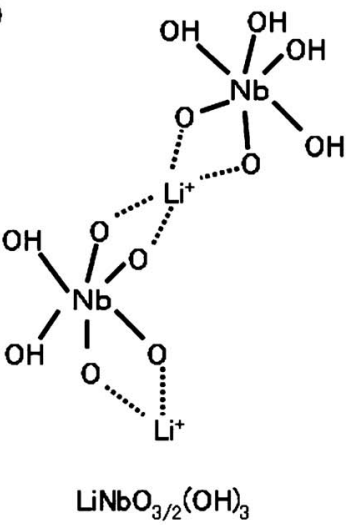

Fig. 2. Possible structure of the precursor molecule, a) stereographic structure and b) chemical structure in detail.

Table 1. Properties of Alkali Metals ${ }^{32), 35)}$

\begin{tabular}{ccc}
\hline Element & $\begin{array}{c}\text { Solubility of Hydroxide } \\
\mathrm{g} / 100 \mathrm{~g} \mathrm{H}_{2} \mathrm{O}\end{array}$ & $\begin{array}{c}\text { Electronegativity } \\
\text { (Pauling) }\end{array}$ \\
\hline $\mathrm{Li}$ & $12.8 \mathrm{~g}$ at $20^{\circ} \mathrm{C}$ & 1.0 \\
$\mathrm{Na}$ & $109 \mathrm{~g}$ at $20^{\circ} \mathrm{C}$ & 0.9 \\
$\mathrm{~K}$ & $112 \mathrm{~g}$ at $20^{\circ} \mathrm{C}$ & 0.8
\end{tabular}

aluminum on sapphire (001) substrate, because the aluminum pattern was dissolved by the alkaline coating solution. We investigated the neutralization of the precursor solution using formic acid, acetic acid and hydrochloric acid. Acetic acid was found to be the best neutralizer for the precursor solution when preparing dense $\mathrm{LiNbO}_{3}$ films with high crystallinity.

Figure 3 shows titration curve for neutralization of 0.1 $\mathrm{mol} / \mathrm{L} \mathrm{Li}-\mathrm{Nb}$ hydroxide solution by $0.1 \mathrm{~N}$ acetic acid. The starting $\mathrm{pH}$ of the $\mathrm{Li}-\mathrm{Nb}$ hydroxide solution was 11 . Neutralization of $10 \mathrm{ml}$ of $0.1 \mathrm{~mol} / \mathrm{L} \mathrm{Li}-\mathrm{Nb}$ hydroxide solution took $31 \mathrm{ml}$ of $0.1 \mathrm{~N}$ acetic acid and finished at $\mathrm{pH}$ 6.8. If the $\mathrm{Li}-\mathrm{Nb}$ hydroxides have six hydroxy groups, as $\mathrm{LiNb}(\mathrm{OH})_{6}$, neutralization should take $60 \mathrm{ml}$ of acetic acid. Consequently, half of the hydroxy groups are dissociated in ionic equilibrium, confirming the chemical structure of the precursor molecule $(\mathrm{Li}$ $\left.\left[\mathrm{NbO}_{3}(\mathrm{OH})_{3}\right]^{3-}\right)$ shown in Fig. 2(b). The hydroxy groups in Li-Nb hydroxide can be substituted by acetate groups. The dissociation constant $\mathrm{p} K_{\mathrm{b}}$ is estimated to be 5.2. The titration curve has a gentle slope, so that $\mathrm{Li}-\mathrm{Nb}$ hydroxide is a weak base.

Figure 4 shows infrared (IR) spectra of $\mathrm{Li}-\mathrm{Nb}$ hydroxide gels (Fig. 4(a)) and Li-Nb hydroxide acetate gels (Fig. 4 (b)). The IR spectrum of the Li-Nb hydroxide gels shows strong absorption bands, ascribed to the hydroxy groups, at $1650 \mathrm{~cm}^{-1}$ and $3400 \mathrm{~cm}^{-1}$, and an absorption band ascribed to carbonate ions derived from $\mathrm{CO}_{2}$ at $1430 \mathrm{~cm}^{-1}$. The IR spectrum of the Li-Nb hydroxide acetate gels shows absorption bands, ascribed to acetate groups, at $1430 \mathrm{~cm}^{-1}$ and 1580 $\mathrm{cm}^{-1}$.

Doeuff et al. have studied IR spectra in order to clarify the role of the acetate group as a ligand to the precursor molecule during hydrolysis of the titanium alkoxides.36) I R spectra of the acetate ligand coordinating to the precursor molecule have two absorption bands due to a symmetric vibration $\left.\left(v_{\text {sym }(\mathrm{COO})}\right)\right)$ and an antisymmetric vibration $\left(v_{\text {asym }(\mathrm{COO})}\right)$. 


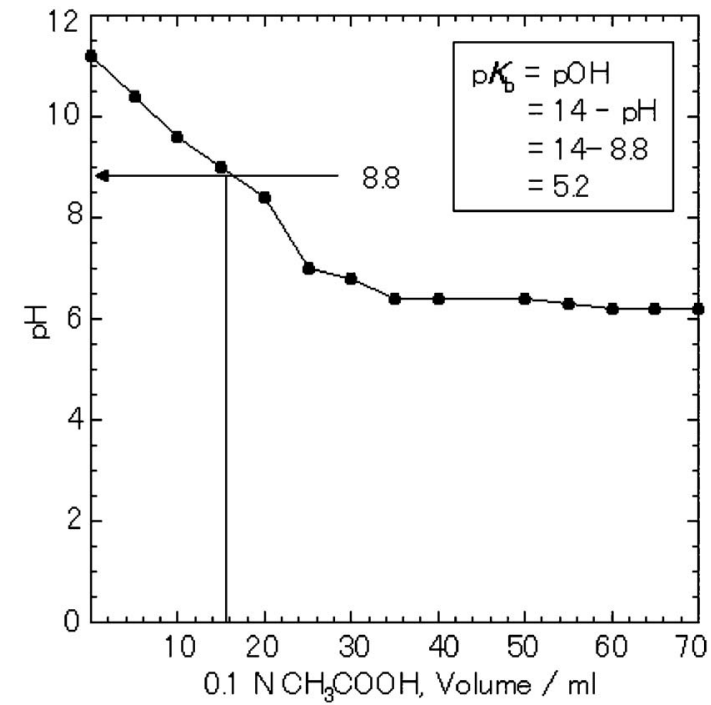

Fig. 3. Titration curve for neutralization of $0.1 \mathrm{~mol} / \mathrm{L} \mathrm{Li}-\mathrm{Nb}$ hydroxide solution by $0.1 \mathrm{~N}$ acetic acid.

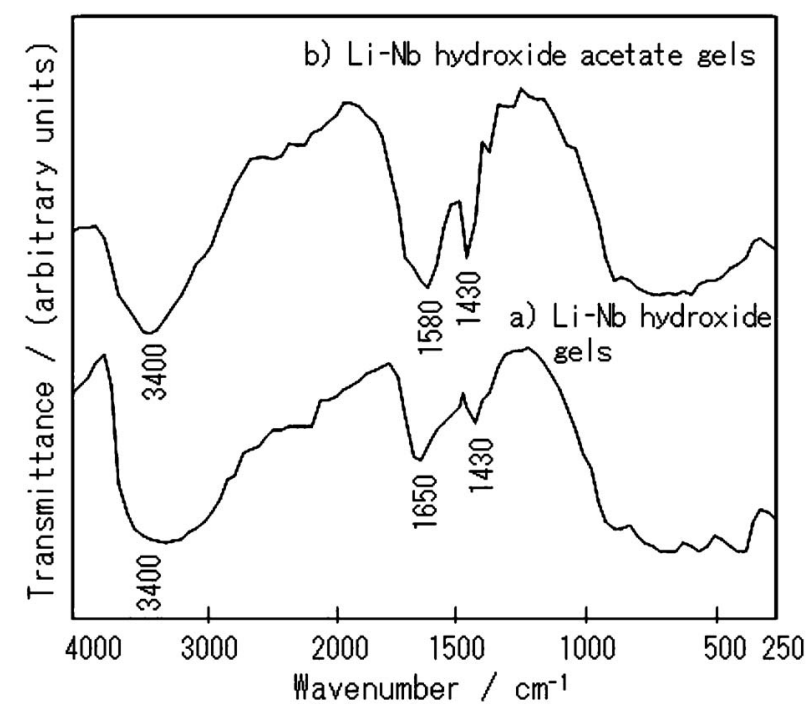

Fig. 4. IR spectra of a) Li-Nb hydroxide gels and b) $\mathrm{Li}-\mathrm{Nb}$ hydroxide acetate gels.

How the acetate ligand coordinates to the precursor molecule is speculated according to the frequency separation $(\Delta v)$ between the symmetric vibration $\left.\left(v_{\text {sym }(\mathrm{COO})}\right)\right)$ and the antisymmetric vibration $\left(v_{\text {asym }(\mathrm{COO})}\right)$. Bridging acetates usually give $\Delta v$ values in the range $120-160 \mathrm{~cm}^{-1} .^{36)}$ In the IR spectrum in Fig. $4(\mathrm{~b})$, the frequency separation $(\Delta v)$ between $1430 \mathrm{~cm}^{-1}\left(v_{\text {sym }(\mathrm{COO})}\right)$ and $1580 \mathrm{~cm}^{-1}\left(v_{\mathrm{asym}(\mathrm{COO})}\right)$ is 150 $\mathrm{cm}^{-1}$, which indicates bidentate bridging acetates. Therefore, acetate ions may substitute for hydroxy groups in the precursor molecule, to coordinate as bridging acetate groups. The precursor molecule complex in gel film may have the conformation of the bridging acetate ligand shown in Fig. 5 .

\section{Processing and characterization of $\mathrm{LiNbO}_{3}$ and $\mathrm{KLN}$} films

3.1 $\mathrm{LiNbO}_{3}$ films ${ }^{16)-19)}$

$\mathrm{LiNbO}_{3}$ gel films are prepared from the aqueous precursor solution crystallized on sapphire (001) substrate by heating

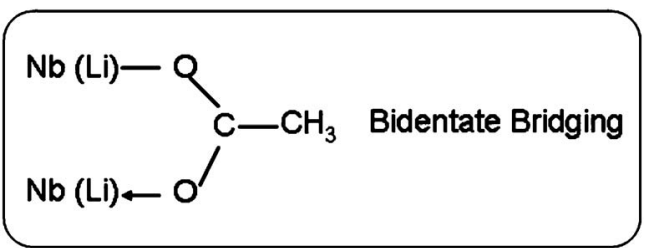

Fig. 5. Acetate ligand coordination to the precursor molecule.

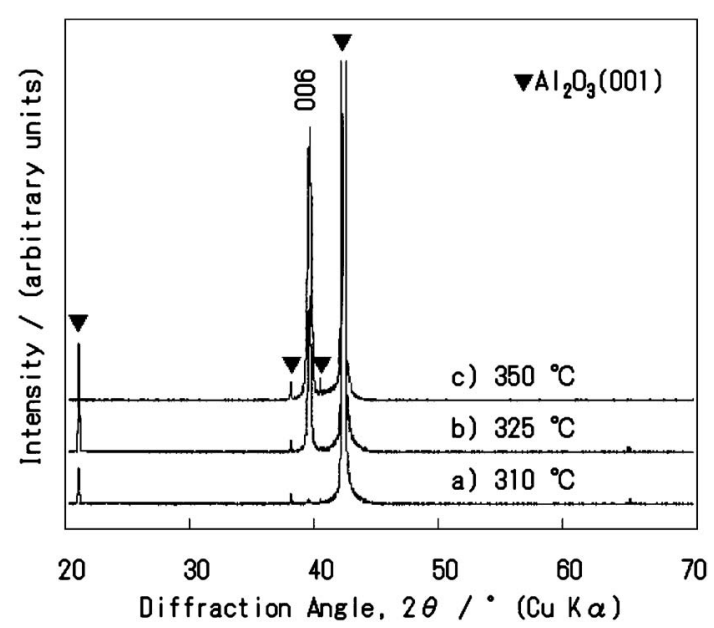

Fig. 6. X-ray diffraction (XRD) profiles of $\mathrm{LiNbO}_{3}$ films prepared on sapphire (001) substrates by heat-treatment at a) $310^{\circ} \mathrm{C}$, b) $325^{\circ} \mathrm{C}$ and c) $350^{\circ} \mathrm{C}$.

above $325^{\circ} \mathrm{C}$, and exhibited highly preferred (006) orientation (Fig. 6). This low crystallization temperature can be achieved because the gel film contains no carbon residues, and the precursor molecule may have the structure of -O- $\mathrm{Li}-\mathrm{O}-$ $\mathrm{Nb}-\mathrm{O}$ - bonds with the $\left[\mathrm{NbO}_{3}(\mathrm{OH})_{3}\right]^{4-}$ octahedra, i.e. the skeletal structure in the $\mathrm{LiNbO}_{3}$ crystal.

We observed the textures of the films prepared by heattreatment at various temperatures, using scanning electron microscopy (SEM). We found that the film prepared at $325^{\circ} \mathrm{C}$ had some pores on its surface, but the film prepared at $350^{\circ} \mathrm{C}$ had a smooth surface, free from cracks and pores. Grain growth began in the films with heat-treatment at $600^{\circ} \mathrm{C}$. The appropriate heat-treatment temperatures are therefore in the range $350-500^{\circ} \mathrm{C}$ for the preparation of crystalline films with smooth surfaces.

X-ray photoelectron spectroscopy along the depth of the film revealed the composition of the films was homogeneous, with no irregularity in the interface between film and substrate.

$\mathrm{LiNbO}_{3}$ films also crystallized with strong orientation on sapphire substrates using the neutralized precursor solution by heating above $350^{\circ} \mathrm{C}$. Dense and smooth $\mathrm{LiNbO}_{3}$ films are prepared by the heat-treatment at $500^{\circ} \mathrm{C}$. When neutralized precursor solution is used, heat-treatment at $500^{\circ} \mathrm{C}$ is necessary to burn out carbon residues derived from acetate groups.

The optical properties of the $\mathrm{LiNbO}_{3}$ films were determined by measuring the optical losses $(632.8 \mathrm{~nm})$. The optical loss of the $\mathrm{LiNbO}_{3}$ film $(\sim 500 \mathrm{~nm})$ prepared at $500^{\circ} \mathrm{C}$ was $6 \mathrm{~dB} /$ $\mathrm{cm}$ in the $\mathrm{TE}_{0}$ mode. Annealing of $\mathrm{LiNbO}_{3}$ films $(670 \mathrm{~nm})$ in oxygen for $2 \mathrm{~h}$ was very effective in reducing the optical losses, to $2 \mathrm{~dB} / \mathrm{cm}$ in the $\mathrm{TE}_{0}$ mode and $4 \mathrm{~dB} / \mathrm{cm}$ in the $\mathrm{TM}_{0}$ mode.

3-dimensional $\mathrm{LiNbO}_{3}$ film waveguides were fabricated by a 


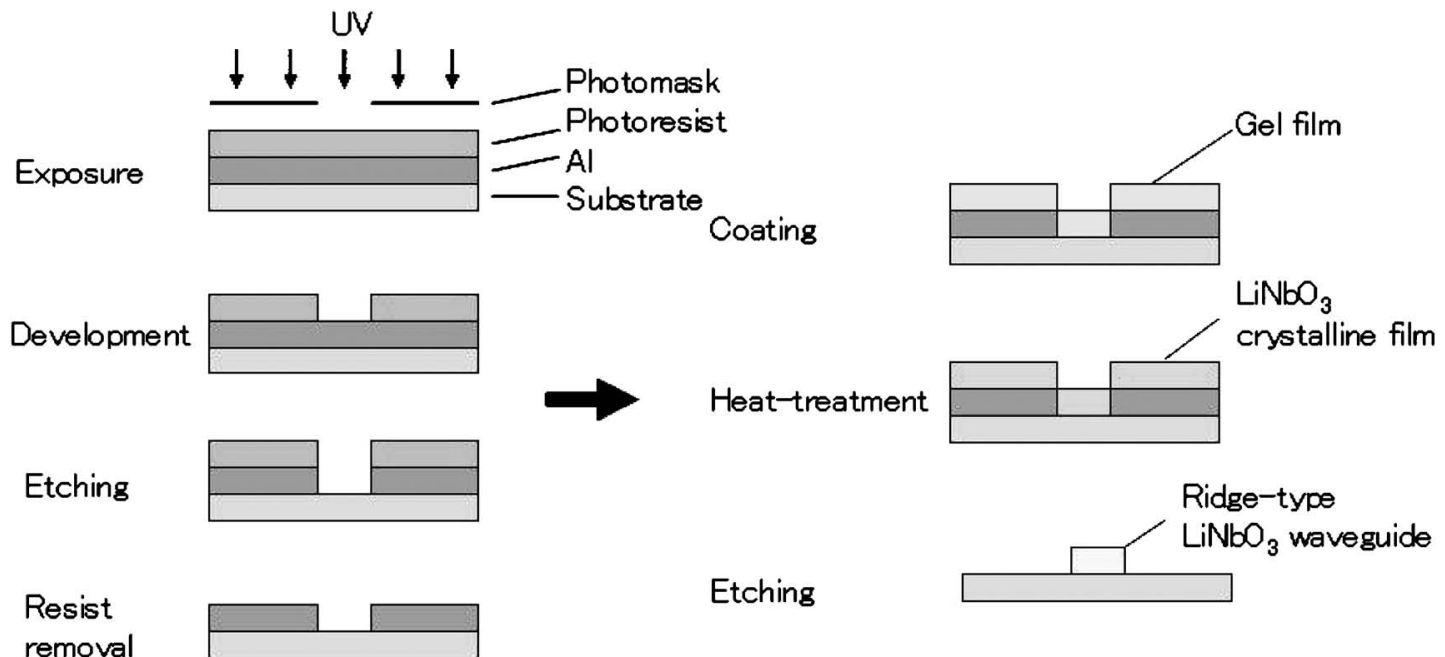

Fig. 7. Patterning process of $\mathrm{LiNbO}_{3}$ thin films.

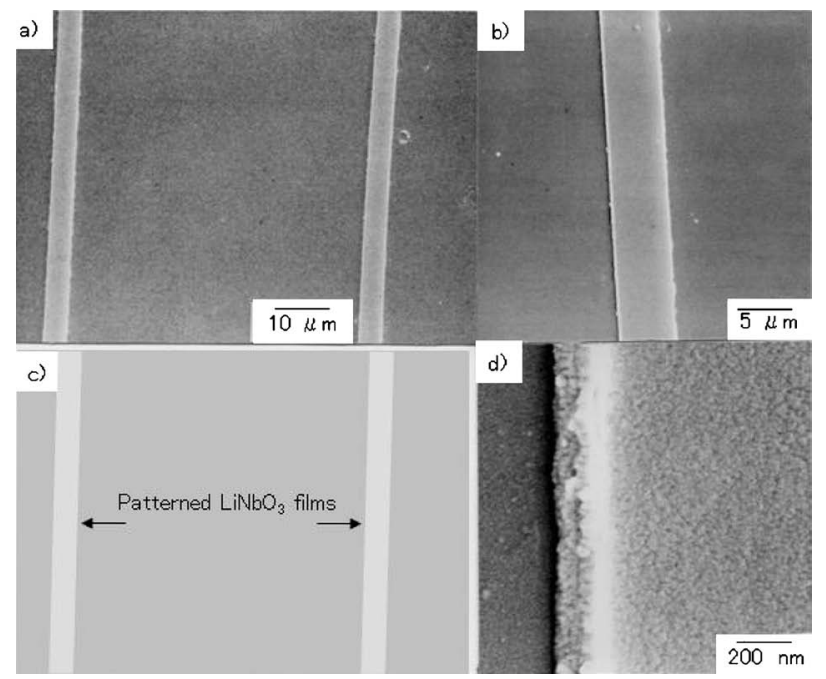

Fig. 8. SEM images of the patterned $\mathrm{LiNbO}_{3}$ waveguide prepared on sapphire (001) substrate prepared at $500^{\circ} \mathrm{C}$, a) fabrication pattern, b) a higher magnification of the waveguide, c) schematic of the $\mathrm{LiNbO}_{3}$ waveguide, d) edge region of the waveguide.

combination of the coating method using the neutralized precursor solution, and the patterning technique using photolithography (Fig. 7). The aluminum masked substrate was fabricated by photolithography. Gel film was then coated on the aluminum masked substrate using neutralized precursor solution. The gel film crystallized into $\mathrm{LiNbO}_{3}$ films by heattreatment at $500^{\circ} \mathrm{C}$. A ridge-type $\mathrm{LiNbO}_{3}$ waveguide was fabricated after the aluminum was removed by etching. Figure 8 shows SEM images of the patterned $\mathrm{LiNbO}_{3}$ waveguide prepared on sapphire (001) substrate using a photomask, which has a pattern of $4 \mu \mathrm{m}$ wide twin lines. The patterned $\mathrm{LiNbO}_{3}$ films were fabricated as the photomask pattern. The surface of the patterned $\mathrm{LiNbO}_{3}$ film appeared to be smooth and free from cracks, and the ridge region was also fabricated accurately.

3.2 KLN films ${ }^{20), 21)}$

The aqueous precursor solution for KLN films was prepared using the water soluble $\mathrm{Li}-\mathrm{Nb}$ precursor molecule. As described in section 2.2 , the $\mathrm{K}-\mathrm{Nb}$ hydroxide is scarcely dis-

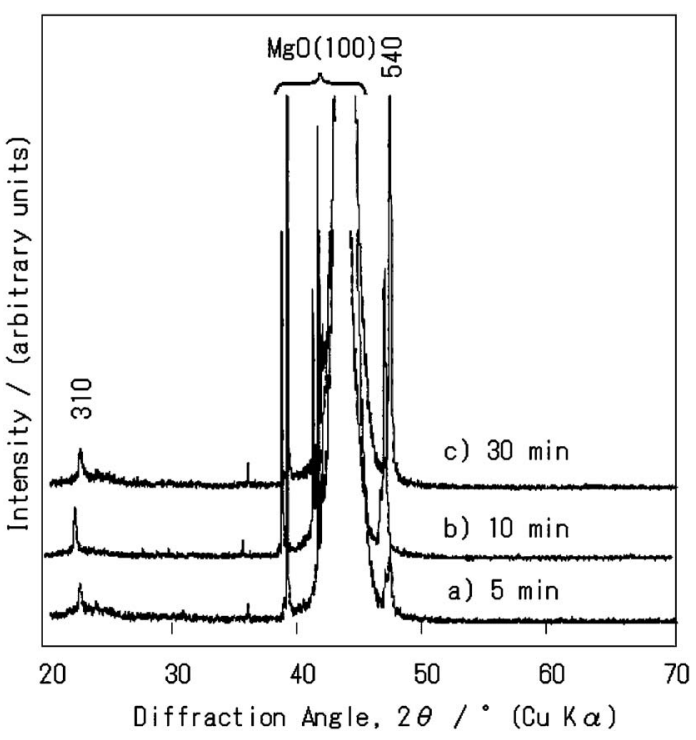

Fig. 9. XRD profiles of KLN films prepared on $\mathrm{MgO}(100)$ substrate at $700^{\circ} \mathrm{C}$ using rapid heating and cooling process, a) $5 \mathrm{~min}$, b) $10 \mathrm{~min}$ and c) $30 \mathrm{~min}$.

solved in water. $\mathrm{K}-\mathrm{Li}-\mathrm{Nb}$ aqueous solution cannot be prepared directly from the $\mathrm{K}-\mathrm{Li}-\mathrm{Nb}$ hydroxide via complete hydrolysis of the $\mathrm{K}-\mathrm{Li}-\mathrm{Nb}$ triple alkoxide. Lithium ethoxide with a molar ratio 0.4 , and niobium ethoxide with a molar ratio 1 , were therefore dissolved in ethanol under nitrogen atmosphere, followed by refluxing for $20 \mathrm{~h}$ to prepare the double alkoxide in advance. The $\mathrm{Li}_{0.4}-\mathrm{Nb}$ hydroxide precipitate was obtained by complete hydrolysis of the double alkoxide. The $\mathrm{K}_{0.6}-\mathrm{Li}_{0.4}-\mathrm{Nb}$ aqueous precursor solution was prepared by dissolving the hydroxide precipitate in potassium hydroxide solution with a molar ratio 0.6 .

We investigated the crystallinity and morphology of KLN films prepared on $\mathrm{MgO}$ (100) substrates by heat-treatment at various temperatures using the aqueous precursor solution. Rapid heating and cooling in the heat-treatment process was very effective in controlling the crystallization orientation and grain growth in KLN films. KLN film was found to crystallize with highly preferred (540) orientation on $\mathrm{MgO}$ (100) substrate by heat-treatment at $700^{\circ} \mathrm{C}$ for $30 \mathrm{~min}$ (Fig. 9). SEM 

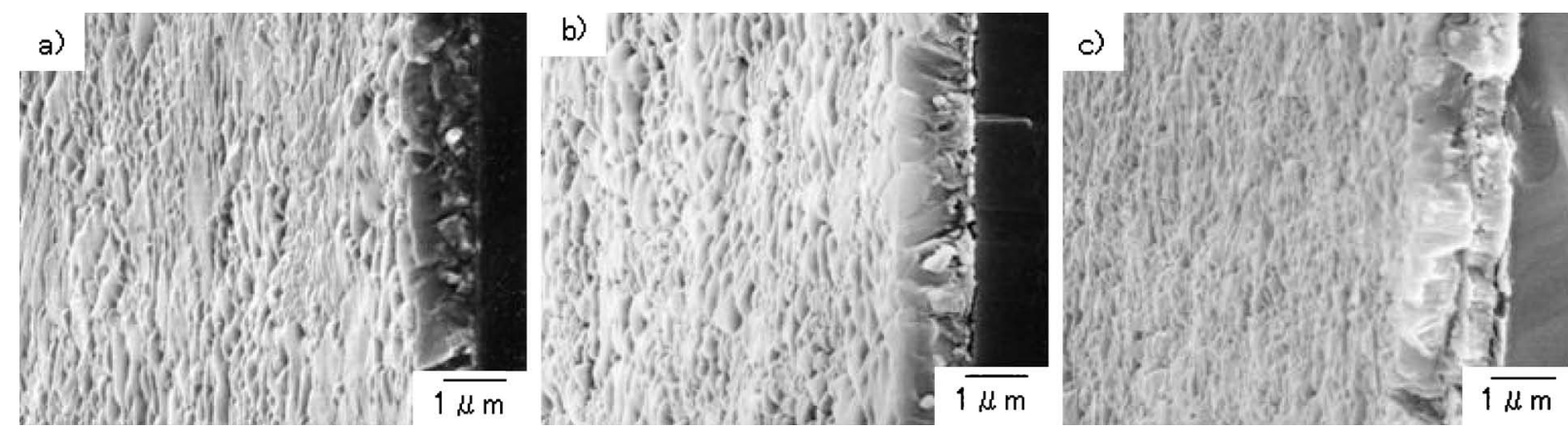

Fig. 10. SEM images of $1 \mu \mathrm{m}$ thick KLN films prepared on a) $\mathrm{MgO}(100)$, b) $\mathrm{Pt}(100) / \mathrm{MgO}(100)$ and c $) \mathrm{Pt}(111) / \mathrm{Ti} / \mathrm{SiO} 2 / \mathrm{Si}(110) \mathrm{substrates}$.

observation showed that the film consisted of homogeneous grains. The Raman spectrum indicated that the crystalline structure of the KLN films was tetragonal. The KLN films were found to crystallize with (310) and (540) preferred orientations on $\mathrm{MgO}$ (100) substrates by repeating the coating and heating processes to increase the thickness of the film. $1 \mu \mathrm{m}$ thick KLN films without defects were successfully prepared on $\mathrm{MgO}(100), \mathrm{Pt}(100) / \mathrm{MgO}(100)$ and $\mathrm{Pt}(111) / \mathrm{Ti} /$ $\mathrm{SiO}_{2} / \mathrm{Si}(110)$ substrates (Fig. 10).

The dielectric properties of the KLN film prepared on $\mathrm{Pt}$ (100) $/ \mathrm{MgO}(100)$ substrate were $\varepsilon^{\prime}=136, \tan \delta=0.026$ at $1 \mathrm{kHz}$. The $\varepsilon^{\prime}$ value of the KLN film is reasonable compared to the dielectric constants of the KLN single crystal, $\varepsilon_{11}(306)$ and $\varepsilon_{33}(115)$.

\section{Application of aqueous precursor solution to the process- ing of lead-free piezoelectric ceramics}

Highly oriented crystalline $\mathrm{LiNbO}_{3}$ and KLN films were successfully prepared using the aqueous precursor solutions by heat-treatment at low temperatures. The composition of alkali metals is readily controlled in the aqueous precursor solutions. The aqueous precursor solutions can therefore be expected to be used to prepare powders and films with excellent properties as $(\mathrm{K}, \mathrm{Na}, \mathrm{Li}) \mathrm{NbO}_{3}$ piezoelectric ceramics.

Ceramic bulks are usually processed by the sintering of a green body molded from ceramic powder and binders. We propose a novel processing method of a monolithic bulk using the aqueous precursor solution. We found that a transparent gel was formed by neutralizing the aqueous solutions. Monolithic gel may therefore be obtained by exploring the drying and heating processes. A crystalline, dense and monolithic bulk without cracks can be prepared by heat-treatment at low temperatures, which is expected to have good piezoelectric properties.

\section{Conclusions}

(1) Li-Nb hydroxide aqueous solution can be used as a precursor solution for coating. The gel films prepared from the aqueous $\mathrm{Li}-\mathrm{Nb}$ precursor solution contain no carbon residues; this is one reason why the $\mathrm{LiNbO}_{3}$ films can be synthesized by heat-treatments at low temperatures as low as $325^{\circ} \mathrm{C}$. A further reason is that the precursor molecule has -O-Li-O-Nb-O- bonds with $\left[\mathrm{NbO}_{3}(\mathrm{OH})_{3}\right]^{4-}$ octahedral structure, that is a skeletal structure in the $\mathrm{LiNbO}_{3}$ crystal.

(2) The $\mathrm{Li}-\mathrm{Nb}$ precursor molecule is considered to be an oligomer that gives water solubility as a result of the hydroxy groups surrounding the molecule. Half of the hydroxy groups in the precursor molecule are dissociated in ionic equilibrium, and can be substituted with acetate groups.
(3) The solubility of the alkali-metal-Nb hydroxide after complete hydrolysis of the double alkoxide decreases as $\mathrm{Li}>$ $\mathrm{Na}>\mathrm{K}$. Although the $\mathrm{K}-\mathrm{Nb}$ hydroxide is scarcely soluble in water, the aqueous precursor solution for KLN films can be prepared by dissolving the $\mathrm{Li}-\mathrm{Nb}$ hydroxide in potassium hydroxide solution.

(4) $\mathrm{LiNbO}_{3}$ and KLN films crystallize with dense and highly preferred orientation by heat-treatment at low temperatures using the aqueous precursor solutions; these films have excellent optic and electric properties. $\mathrm{LiNbO}_{3}$ patterned films can be fabricated using the photolithography technique.

(5) The alkali composition of lithium, sodium and potassium can easily be controlled in the aqueous precursor solution. As a result, high quality piezoelectric ceramics and films of $(\mathrm{K}, \mathrm{Na}, \mathrm{Li}) \mathrm{NbO}_{3}$ may be synthesized using these aqueous precursor solutions.

\section{References}

1) S. Hirano, K. Kikuta and K. Kato, Mater. Res. Symp. Proc., 200, 3-11 (1990).

2) S. Hirano, T. Hayashi, K. Nosaki and K. Kato, J. Am. Ceram. Soc., 72, 707-709 (1989).

3) S. Hirano and K. Kato, Solid State Ionics, 32/33, 765-770 (1989).

4) S. Hirano and K. Kato, J. Non. Cryst. Solids, 100, 538-541 (1988).

5) S. Hirano and K. Kato, Adv. Ceram. Mater., 3, 503-506 (1988).

6) S. Hirano and K. Kato, Adv. Ceram. Mater., 2, 142-145 (1987).

7) T. Yogo , Y. Takeichi, K. Kikuta and S. Hirano, J. Am. Ceram. Soc., 78, 1649-1652 (1995).

8) K. Kikuta, Y. Isobe, T. Yogo, S. Ono and S. Hirano, J. Am. Ceram. Soc., 79, 2289-2292 (1996).

9) S. Hirano, T. Y. Takeichi, W. Sakamoto and T. Yogo, J. Cryst. Growth., 237-239, 2091-2097 (2002).

10) K. Nashimoto, H. Moriyama and E. Osakabe, Jpn. J. Appl. Phys., 35, 4936-4940 (1996).

11) K. Terabe, A. Gruverman, Y. Matsui , N. Iyi and K. Kitamura, J. Mater. Res., 11, 3152-3157 (1996).

12) N. L. Jeon, P. G. Clem, R. G. Nuzzo and D. A. Payne, J. Mater. Res., 10, 2996-2999 (1995).

13) P. G. Clem, Z. Xu and D. A. Payne, Mater. Res. Symp. Proc., 401, 249-254 (1996).

14) V. Joshi and M. Mecartney, J. Mater. Res., 8, 2668-2678 (1993).

15) T. A. Derouin, C. D. E. Lakeman, X. H. Wu, J. S. Speck and F. F. Lange, J. Mater. Res., 12, 1391-1400 (1997).

16) S. Ono, T. Takeo and S. Hirano, J. Am. Ceram. Soc., 79, 1343-1350 (1996).

17) S. Ono and S. Hirano, J. Am. Ceram. Soc., 80, 2533-2540 (1997). 
18) S. Ono and S. Hirano, J. Am. Ceram. Soc., 80, 2869-2875 (1997).

19) S. Ono, O. Böse, W. Unger, Y. Takeichi and S. Hirano, J. Am. Ceram. Soc., 81, 1749-1756 (1998).

20) S. Ono and S. Hirano, J. Ceram. Soc. Japan, 106, 850-854 (1998).

21) S. Ono , N. Yamada and S. Hirano, J. Am. Ceram. Soc., 84, 1415-1420 (2001).

22) J.-F. Li, K. Wang, B. P. Zhang, and L. M. Zhang, J. Am. Ceram. Soc., 89, 706-709 (2006).

23) Y. Zhen and J.-F. Li, J. Am. Ceram. Soc., 89, 3669-3675 (2006).

24) H. Birol, D. Damjanovic and N. Setter, J. Eur. Ceram. Soc., 26, 861-866 (2006).

25) E. Hollenstein, M. Davis, D. Damjanovic and N. Setter, Appl. Phys. Lett., 87, 182905 (2005).

26) M. Matsubara, T. Yamaguchi, W. Sakamoto, K. Kikuta, T, Yogo and S. Hirano, J. Am. Ceram. Soc., 88, 1190-1196 (2005).

27) M. Matsubara, K. Kikuta and S. Hirano, J. Appl. Phys., 97,
114105 (2005).

28) Y. Saito, H. Takao, T. Tani, T. Nonoyama, K. Takatori, T. Homma, T. Nagaya and M. Nakamura, Nature, 432, 84-87 (2004).

29) R. P. Wang, R. J. Xie, T. Sekiya and Y. Shimojo, Mater. Res. Bull., 39, 1709-1715 (2004).

30) Y. Guo, K. Kakimoto and H. Osato, Appl. Phys. Lett., 85, 4121-4123 (2004).

31) S. Ono and H. Tsuge, Proc. Int. Symp. on Eco Topia Science 2007, ISETS07, Nov. 23-25, Nagoya, Japan (2007) in press.

32) Y. Niimura, "Mukikagaku Kakuron," Asakura Publishing Co., Ltd. (1973) p. 113 [in Japanese].

33) F. A. Cotton and G. Wilkinson, "Advanced Inorganic Chemistry 5th ed.," John Wiley \& Sons Inc. (1988) p. 789.

34) D. J. Eichorst, D. A. Payne, S. R. Wilson and K. E. Howard, Inorg. Chem., 29, 1458-1459 (1990).

35) "Kinzoku Data Book 4th ed.," ed. by The Japan Institute of Metals, Maruzen Co., Ltd. (2004) p. 19 [in Japanese].

36) S. Doeuff, M. Henry, C. Sanchez and J. Livage, J. Non-Cryst. Solids, 89, 206-216 (1987). 